\title{
Difficulties and Misconceptions of Students in Learning Limit
}

\author{
Krishna Prasad Adhikari \\ krishnaprasad.adhikari@tucded.edu.np \\ Lecturer \\ Central Department of Education
}

\begin{abstract}
The purpose of this study is to explore the difficulties and misconceptions of secondary level students in learning limit of the function. In this study, which used mix-method design, regarding difficulties and misconceptions, a concept test was used on 200 grade XII students of Kathmandu Metropolitan City of Nepal, and interviews were conducted on 12 purposively selected students from 200 students. The data obtained from the test was categorized as the category of the responses and interpreted using a percentage score. In addition to that, the data obtained from the interview was analyzed and interpreted by using a general qualitative approach. The finding of the study revealed that student's difficulties in solving a limit problem have aroused because of the lack of conceptual clarity on the limit of the function. Similarly, the student has misconception on indeterminate and infinite, limiting and functional value of the function, and symbolic representation of infinity.
\end{abstract}

Key Words: Limit, instrumental understanding, relational understanding, misconception.

\section{Introduction}

Concept of limit for grade XI Nepalese students is a new and completely unfamiliar area of mathematics. As a mathematics teacher, I realized most of the students of grade XI take calculus as a difficult area of mathematics. Very few students attempt the questions from the calculus part in examination also. Almost calculus concepts require a good knowledge of the limit of the function. Lam (2009) observed that students encounter epistemological problems with the limit concept and that these problems emanated from language and symbolism used. My experiences direct the common misunderstanding on students that occur in calculus due to lack of visualization on a definition of limit, continuity, and derivative and their interrelations (Robert \& Speer, 2001; Areaya \& Sidelil, 2012).

Mathematical knowledge is cumulative because it builds new knowledge based on previous content. Students can do better in higher study if they have a clear understanding of the basic concept of mathematics. Generally, in the transition between one level of education to another most of the students unable to regard the values of their previous knowledge, and ultimately it causes forgetting of the concept (Muzangwa \& Chifamba, 2012). Tall (1991), proclaimed that due to this transition students unable to keep a balance between preexisting cognition and new 
experiences of knowledge and hence creates a dilemma, misunderstanding, and misconception. He emphasized the two terms assimilation and accommodation where students take in new ideas and students' cognitive structure should be modified to adapt to the new learning situation. Dewey (1945) pointed out that new objects and events should be related intellectually to those of earlier experiences (as cited in Eade, 2003). So, the mathematical knowledge should be constructed from related knowledge which is already gained by the learner.

As discussed by Hiebert \& Carpenter (1992), learning along with understanding is an important aspect of mathematics education and it is generally accepted that this type of learning only possible when pieces of knowledge are conceptually connected. The new knowledge can be created, dissolved, or changed based upon the interconnectivity among the preexisting cognitive structure of students with a new idea. Thus, knowledge is seen as a web between preexisting structure and new learning experiences. Every higher mathematical content has developed from some foundational concepts, which are crucial to learning a higher concept. For example, to learn content such as derivative, integration, analysis, etc. the learner needs the concept of the functional value and limiting values. Similarly, the concept of set theory is very essential; to learn group, ring, field, etc. Alam (2020) asserted that student unable to perform well in calculus not because they find it tough to learn it or that lack the potential owing to its complexity but because they lack the skills and fundamentals of precalculus including a deficiency of skillfulness, knowledge, and command over trigonometry, algebra, logarithms, and other essential concepts.

Tall (1991) has categorized cognitive development into three separates but interconnected worlds, named as a "conceptual-embodied world, perceptual-symbolic world, and formal-axiomatic world". He further labeled the conceptual-embodied world as the mathematical concept that is perceived through the intellect. After that, every individual construct mental map of mathematical concepts by using his/her physical perceptions (Juter, 2006). Whereas the perceptual-symbolic world is concerned with the capacity to apply symbols in doing mathematics. The symbols are the tools which switch doing mathematics to thinking mathematics (Tall, 2004). The symbols represent both the processes and concepts. The world formal-axiomatic deals on the axiomatic system used in the mathematical structure that is expressed in terms of formal definition. Individuals arrive in this world while their mental representations of concepts are formed and can encapsulate the processes as objects and can go beyond the percept to the formal definitions (Tall, 2004; Juter, 2006). For the conceptual understanding of any content, the learner should be able to comprehend mathematical concepts, operations, and relations among mathematical structures (Kilpatrick et al., 2001; Watson \& Sullivan, 2008).

According to Skemp (1979), mathematical understanding can be categorized into instrumental, relational, and logical understanding. The concept which deals with the ability to apply an appropriate rule and formula to solve the problem without any rationale behind it is instrumental understanding. The capacity of the learners to relate the definitions and formulae in establishing general mathematical understanding is termed as logical understanding. In this, the learner knows why to apply formulae and how. At last, the ability of a learner in which he/she can connect different mathematical symbolism and notation in the chains of logical reasoning is understood as logical understanding. These three categories are taken as the basis of analyzing data in this study. 
The errors and misconceptions may occur during the process of learning new mathematical content. Misconceptions exist in varying degrees in all disciplines (Brown, 1992) including mathematics. In mathematics, misconceptions exist in the understanding of mathematical concepts and their applications in solving problems. Besides the difficulties in understanding, this paper also attempted to determine the degree of misconceptions and concept of limit of a function that acquired by the students at grade XII in learning as the base to learn calculus.

One interesting finding derived from the study of Kula \& Guzel (2013) that knowledge on misconception is essential for teachers as well to interpret students' ideas and to prepare an effective instruction plan. To prevent misconceptions first teachers should know to determine and eliminate the possible misconceptions that would be developed on students. Regarding the most common misconception, they found that was about the value of never being reachable.

Misconceptions are incorrect notions and many students are disposed to perceiving them as correct. The key characteristics of misconceptions are that students themselves construct alternative definitions for the concepts studied; most of them believe this as scientific fact, and it is difficult to change such incorrect dogmas (Fisher, 1985). These are misunderstandings and misinterpretations based on incorrect meanings. According to Ojose (2015), students make errors in two forms: conceptual and execution errors. Conceptual errors, at first, occur due to the failure of recognizing structural relationships in the problem or to catch the principles required for its solution. Secondly, execution errors happen when an effort to use some procedure breakdown or is only partially executed.

I realized from my experience that certain misconceptions acquired by students in earlier mathematical learning do not necessarily get removed by the teaching of later concepts. Teaching limit concept in the first year does not guarantee remediation of underlying function concepts. To overcome these difficulties teachers should detect the misconception on function and start teaching. It is imperative for teachers to works on detecting the existing misconception on students and should accept that students can overcome the misconceptions by planning and deliberately providing opportunities for students through effective teaching strategies (Ojose, 2015). For instance, the lack of essential understanding of the historical development of the limit concepts and its connection with the development of calculus can cause potential misconceptions in doing the problems related to the limit of the function. Furthermore, misconceptions develop because of the learning or instruction about the limit concept. Misconceptions are also the result of inadequate understanding of the basic forms of calculus like the limit of functions and their representation (Muzangwa \& Chifamba, 2012). Tall (2004), indicated that language and thought are closely knotted. The role of language in the construction and maintenance of misconceptions has received considerable attention in research.

As suggested by the related literature, concept formation is crucial in the first years of learning new and unfamiliar content. Tall (1991) categorized three cognitive development worlds while Skemp (1979) devised three levels of mathematical understanding. These two interconnected and sequential concepts are used as a conceptual understanding of the study. Based on these ideas, this study would explore the difficulties and misconceptions of students in learning the 
limit of the function. In my observation, very few studies have focused on this issue. So, this study would provide a fresh interpretation of students' understanding of calculus in the context of Nepal.

\section{Methods and Procedures}

Explanatory sequential mixed method design in which quantitative data informed qualitative data (Creswell, 2015) was used to explore the conception and misconception of the students in learning limit of the function. Creswell (2015) argued that as a methodology, mixed method research focuses on philosophical assumptions or worldviews grounded on pragmatism. Pragmatism can be seen as a means of bridging the gap between the empirical singular scientific approach to research and the newer "freewheeling" inquiry of qualitative research. A theoretical framework such as pragmatism can be pivotal to conduct the research as it focuses on the logical link between the two paradigms of inquiry; quantitative and qualitative.

This study was carried out in Kathmandu Metropolitan City of Nepal where diversity of samples can be achieved through the sampling procedure. Participants of this study were Grade XII students of the academic year 2018/2019 from Science Stream. Students were selected from grade XII because they studied limit in grade XI. Participants were selected by a simple random sampling method for tests and purposively for interviews. Five secondary schools were selected randomly and 40 students from each school were in the sample for the test and 12 students for the interview process.

I applied the test to measure the level of understanding of the students in the limit. The test items were from the prescribed textbook and the study manual. The test items addressed the understanding of students in defining the limit and some examples related to evaluating the limit of the function.

In order to establish the reliability of the instrument, a pilot study was conducted. The test was reliable with a reliability coefficient of 0.83 . After the finalization of the test paper, I conducted an exam in all sample schools with the help of the subject teacher. The responses of students in test items were categorized into correct, partially correct, and incorrect responses. Frequency and percentage were used to analyze and interpret the result.

Subsequently, I developed an interview schedule based on the test result and asked the same questions exactly in the same way and in the same order for all respondents. The interview schedule was structured; nevertheless, it allowed the students to speak freely about how they reason about the concept, thus providing richer data than the student simply marking true or false about something provided by the researcher. Interview conversation was recorded using a smartphone after getting consent from students. After that, I prepared the raw data file in the Nepali language because all interviews were conducted in Nepali medium. My explicit procedure was to read the original transcript of each interview line-by-line repeatedly, underling the responses related to each question that had been asked. Next, I sought to divide the responses into difficulties and misconceptions. Based on these two main themes, I analyzed the responses 
using a general qualitative approach. Confidentiality, anonymity, non-identifiability, and nottraceability were guaranteed in the process of research.

\section{Result and Discussion}

The result of the study was drawn from two sources. In the first stage, a concept test on the limit of the function was applied and an understanding of the students in limit was mapped and explained. After mapping the concept; difficulties and misconceptions were explored using an interview schedule. The result obtained from two stages of study is explained in this section.

\section{Conceptual Understanding of Students on Limit}

The concept test contained questions related to the definition and the use of definition on finding the limit, with subjective type items. Table 1 deals with the students' response to the subjective type questions which were based on the definition of limit, the relation between $\varepsilon, \delta$ in defining the limit, use of the definition of limit to find the limit of the function. The responses of the students in these items were categorized into three categories: Incorrect, partially correct, and correct responses.

Table 1. Understanding of the students on Limit

\begin{tabular}{|c|c|c|c|}
\hline Questions & Incorrect & Partial Correct & Correct \\
\hline $\begin{array}{l}\text { 1. What does } \lim _{x \rightarrow a} f(x)=l \\
\text { mean? }\end{array}$ & $111(55 \%)$ & $89(46 \%)$ & $0(0 \%)$ \\
\hline 2. Write the $\varepsilon, \delta$ definition of limit. & $200(100 \%)$ & $0(0 \%)$ & $0(0 \%)$ \\
\hline 3. What is the relation between $\varepsilon, \delta$ ? & $200(100 \%)$ & $0(0 \%)$ & $0(0 \%)$ \\
\hline $\begin{array}{l}\text { 4. Use the definition of a limit to show } \\
\text { the following: } \lim _{x \rightarrow 2}(5-2 x)=1\end{array}$ & $75(38 \%)$ & $55(27 \%)$ & $70(35 \%)$ \\
\hline $\begin{array}{l}\text { 5. Determine the limit of: } \\
\lim _{x \rightarrow 3} \frac{x^{5}-3^{5}}{x-3}\end{array}$ & $85((42 \%)$ & $73(37 \%)$ & $42(21 \%)$ \\
\hline $\begin{array}{l}\text { 6. Find the limit of the function } \mathrm{f}(\mathrm{x})= \\
\frac{|x|}{x} \text { at } x=0\end{array}$ & $145(72 \%)$ & $35(18 \%)$ & $20(10 \%)$ \\
\hline
\end{tabular}

Table 1 depicts that only about $45 \%$ of students can partially explain the meaning of the limit. This result indicates more than half of the students do not have a clear understanding on the limit of the function. In this question, no one can write the definition of limit by using $\varepsilon, \delta$. That means students do not have any concept of $\varepsilon, \delta$ and it is very hard for students (Tall, 1991). Although they did not have a clear concept on the definition and meaning of limit, most of the students attempted partially and correctly the questions no. four and five which are about calculating the limit. But question six which is based on the left- and right-hand limit concept could not solve by most of the students.

The above interpretation of the result shows that students only have instrumental understanding rather than relational and logical understanding (Skemp, 1979). That means students are 
conceptually weak in calculus. Question five is related to the concept of limit theorem $\lim _{x \rightarrow a} \frac{x^{n}-a^{n}}{x-a}=n a^{n-1}$ but only a few $(10 \%)$ students used this theorem to solve the problem and other (11\%) used factorization method and the rest of them could not solve. Similarly, the last question of the test required the concept of absolute value but very few (10\%) students were able to solve this problem. In analyzing the answer to these questions, it can be said that most of the students have only mechanical skill i.e. instrumental understanding and they did not have a relational concept on different concepts of mathematics.

The concept of limit is most important to learn other concepts of calculus more effectively (Ervynck, 1981; Williams, 1991), but our students do not have such a concept which makes the concept of continuity, derivative, and integration easy. In analyzing the answers sheet, I found that students don't have a conceptual understanding of the differences between limiting and functional value of the function (Muzangwa \& Chifamba, 2012).

\section{Difficulties in Understanding Limit}

The results of the interview show that difficulties persist in all the groups of the students (high, middle, and low). Some interviewees reported it is very difficult to state the $\varepsilon, \delta$ definition of the limit i.e. $\lim _{x \rightarrow a} f(x)=l$. A statement such as "I can't recall it, umm, it is difficult". This difficulty was experienced across the three groups this was the view of some good students in the test. But most of the interviewees expressed that they did not know the actual name of these symbols. Their teacher never used and explained this definition of the limit. They only focused on the statement like $\lim _{x \rightarrow a} f(x)=l$ and finding out the limiting value of the function.

As Vinner (1991) the formal definition to the limit concept is very difficult, the majority of those who gave the formal definition were not able to recall it in a satisfactory way mistaking it in various ways in my interview.

To explore the difficulties in learning limit of the function, interview with 12 students were conducted. The students were coded as $\mathrm{S}_{1}, \mathrm{~S}_{2}, \ldots \mathrm{S}_{21}$ in the interview and their interview transcriptions are presented in excerpt form.

$\mathrm{S}_{1}, \mathrm{~S}_{2}, \ldots=$ Students $\quad \mathrm{R}=$ Researcher

Excerpt 1

$R$ : Explain the following definition in your own words: $\lim _{x \rightarrow a} f(x)=l$.

$S_{I}$ : That means as $x$ tends to ' $a$ ' the value of the function is $l$.

$R$ : Is it similar to the value of the function at $x=a$ ?

$S_{I}:$ Umh! Sometimes similar some time different?

$R:$ In which condition it is different?

$S_{I}$ : I don't know that, but I can show it in example.

$R$ : Could you explain the definition by using $\varepsilon, \delta$ ?

$S_{1}$ : What do the symbols mean? I have never seen these signs in mathematics. 
$R$ : Hello B, could you explain the definition in your own words?

$S_{2}$ : I donot know any definition but I can solve the problem relating to the limit and continuity. Continuity is very easy than the limit.

R: Do you know the relation between the limit and continuity?

$S_{2}$ : What relation? I have just known that for the continuity of the function limit must exist but I don't know the causes.

$R$ : Could you explain the limiting value and functional value of the function?

$S_{2}$ : When the limit is given this is limiting value otherwise it is functional value?

$R:$ That means, these two are the same things, yes?

$S_{2}:$ Yes, only the writing style is different.

The students $\left(\mathrm{S}_{1}, \mathrm{~S}_{2}\right)$ are not able to restate the definition of limit. As Vinner (1991) respondents felt the definition of the limit is very difficult for students to understand because of the $\varepsilon, \delta$ approach. The above excerpt also shows that students could not explain the definition of the limit in a satisfactory manner.

The idea of the limit is confusing in the students. Students most probably didn't understand the definition when it was taught. The student has learned the concept but he/she can't use it in his own words. English could be a problem in this instance and this hinders his/her grasp of the mathematical language and the ability to communicate. This finding is also supported by Tall (2004). He reported that some of the usual misconceptions that students have are resulted from the influence of language. More importantly, they treat limiting value and functional value in the same style. This is the lapses found in the concept of limit.

The next question in the interview was concerned with the use of limit conception to calculate the problem. Here, I have discussed one question which can be solved by using factor and remainder theorem or by using the limit theorem. $\lim _{x \rightarrow a} \frac{x^{n}-a^{n}}{x-a}=n a^{n-1}$ The following excerpt relates to the student's understanding on solving the problem: $\lim _{x \rightarrow 3} \frac{x^{5}-3^{5}}{x-3}$.

\section{Excerpt 2}

R: Explain the method that you will use to find the following limit: $\lim _{x \rightarrow 3} \frac{x^{5}-3^{5}}{x-3}$.

$S_{3}$ : This one we can't immediately plug in 3. We have to find a way of factorizing the numerator so that it could cancel out with the $(x-3)$.

R: Why we can't do so?

$S_{3}$ : I do not know the cause, but to solve this type of problem we have to factorize the expression $x^{5}-3^{5}$. But I do not know how to factorize it; we only practice $x^{3}-a^{3}$.

In this stance students only have instrumental understanding. The students know that $x^{5}-3^{5}$ must be simplified but do not know the process of simplification. Most of them have forgotten the 
factor theorem; remainder theorem and long division. This was so in all the cases of the students' answers in a concept test. The following is a typical extract in this regard.

\section{Excerpt 3}

$R$ : Explain the method that you will use to find the following limit: $\lim _{x \rightarrow 3} \frac{x^{5}-3^{5}}{x-3}$.

$S_{4}$ : This one we can't immediately, we have to find a way of factorizing the numerator so that it could cancel out with the (x-3).

$R:$ Why, we have to cancel $(x-3)$ ?

$S_{4}:$ I don't know what the cause is but we have to cancel it.

$R$ : Do you know the theorem $\lim _{x \rightarrow a} \frac{x^{n}-a^{n}}{x-a}=n a^{n-1}$ about calculating the limit?

$S_{4}:$ Oh this theorem! I remember, we studied in grade XI, but I forgot what is the use of this theorem?

R: Didn't you use this theorem in limit questions?

$\mathrm{S}_{4}$ : No, but I remember that we used this theorem in finding the derivative of function by using first principle.

R: Do you think, finding the limit in derivative is different form limit problem?

$\mathrm{S}_{4}$ : I do not know the relation between limit and derivative. They are different chapters.

In this instance, the student thinks of mechanical substitution as in the above excerpt. According to Skemp (1976), students only have instrumental understanding. One surprising aspect expressed by the students is the relation between derivative and limit. They can calculate the limit in both chapters without a clear understanding of the concept. Another important skill required to solve the problem is the application of theorem. But most of the students did not know the application of the theorem in problem-solving. That means they lack the relational understanding between the problem and theoretical concept.

\section{Students' Misconception on Limit of the Function}

To explore the student's misconception in limit the same concept test was used. In checking the answer sheets of the test, different misconceptions were noted. In the interview to identity common conception of students in limit I used some particular example that can connect to the limit concept. I asked the students to comment on the expression $\operatorname{like} \lim _{x \rightarrow \infty} \frac{1}{x}=0$. Some of the responses to the question: "What will happen when $\mathrm{x}$ approaches infinity in this function? were:

$\mathrm{S}_{1}: f(x)$ gets closer to zero. It can't be zero, it just reaches zero.

$\mathrm{S}_{3}$ : When $x$ gets very big, it becomes smaller.

$\mathrm{S}_{4}$ : If $x$ approaches infinity, $f(x)$ also approaches infinity.

$S_{9}$ : The graph of the function approaches the x-axes, but never touch it. 
The students realized that if $x$ becomes very big, the functional value will reach zero, although it will never be zero itself. They all used the value of $f(x)$ and did not think about the limiting value which would be actually being zero or not. The explanation also impliesthat if you divide one by large number, the value will eventually reach zero. Students did not have clear idea about the difference between limiting and functional value of the function.

On the question of whether we can write $f(\infty)=0$, seven of the twelve students answered yes. But two students replied differently as:

$\mathrm{S}_{7}$ : No, well umm, it depends on the formula. Infinity is a symbol representing a number that is very large.

$\mathrm{S}_{12}$ : Yes, if you divide one by numbers getting bigger and bigger, $x$ becomes smaller and smaller and will eventually reach zero.

This indicates, they see the symbol $\infty$ as a number representing big numbers rather than consider symbol for infinity.

The next question was about the meaning of symbolic expression of $\operatorname{limit}_{\lim _{x-2}} f(x)=1$. The purpose of this question was about the conception of students on limiting value and functional value of the function at any specified point. Some of the responses were as follows:

$\mathrm{S}_{6}$ : It means that the limit exists at one.

$S_{8}$ : As $x$ approaches two, the function approach one.

$S_{7}$ : It says when $x$ is two, $f(x)$ is one. So the functional value and limiting value are equal.

$S_{4}$ : It means, $f(x)$ may be approached to 1 but $x$ never approaches 2.

$S_{12}:$ I think, this is wrong, it may be as $x$ tends to one $f(x)$ tends to 2.

Six of the twelve students were confident that the limit must be defined as $\mathrm{x}=2$ to have a limit one. But, the rest of the students have misconception on limiting value and functional value of a function. Student $\mathrm{S}_{12}$ and the other two did not have clear concept on function as well. Student had misconception on the value approaches to and equal to. For instance, $\mathrm{S}_{7}$ had no clear idea on limiting and functional value. The version of student $\left(\mathrm{S}_{4}\right)$ shows that he/she did not know the meaning of limiting value of function. After that, I asked them to draw the figure based on the limit of this function. But, no one can draw the correct picture.

The next question was about the indeterminate form and removal of indeterminate form to calculate the limit. For that students were asked to find the limit of: $\lim _{x \rightarrow 3} \frac{x^{5}-3^{5}}{x-3}$

Some of the responses were as follows:

$\mathrm{S}_{10 \text { : }}$ When we put $\mathrm{x}=3$ it becomes $0 / 0$, which is equal to 0 .

$\mathrm{S}_{11}$ : I think the limit of the function does not exist because it takes $0 / 0$ form. 
$\mathrm{S}_{8}$ : This is $0 / 0$ form so we have to simplify and take the limit of the function.

$\mathrm{S}_{5}$ : This is not the question of limit it is related to continuity.

As $\mathrm{S}_{5}$ three other students do not recognize this problem as a limit problem. That means, they do not have any concept on the relation between continuity and limit. Some other students as $\mathrm{S}_{10}$ haven't had the concept of indeterminate form. But, the other four students as $\mathrm{S}_{8}$ have the concept of indeterminate as well as the process of finding the limit of the function. To understand the process of solving this problem, students should have the concept of functional and limiting value of the function. Why functional value does not exist but limiting value exist? I asked this question to all students but no one have clear answer, which clearly explains the difference between limiting and functional value. In this problem, functional value does not exist but limiting value exist, if this is show where does this value lie? I asked this question further. But, no one can answer this question.

From these excerptions of interview, we can list some misconceptions on the limit as the limit is equal to the functional value at a point, i.e. a limit can be found by a method of substitution only, when one divides zero by zero, the answer is zero, infinity is the large number, etc. Most of the students have the concept that any other number divided by zero is undefined when one rounds a number off, the number gets closer to another number, but does not equal it.

\section{Findings of the Study}

The findings from the concept test reveal that none of the students have a clear concept on the meaning of limit, $\varepsilon, \delta$ definition, and relation between. $\varepsilon$ and $\delta$. Only about $40 \%$ of students solved the problems related to the limit with the concept of indeterminate form, limit theorem, and other related concepts such as absolute value.

Similarly, every interviewee, including those who had made a few errors on the test gave evidence of holding misconceptions and difficulties. In fact, all interviewees reported more difficulty as far as the definition of limit is concerned. A statement such as "I can't state it properly". "It's difficult" were indicated the same. Students did not have the clear concept about number or symbol. They took $\infty$ as large number rather than symbol. Moreover, students have misconception about indeterminate form and infinity. They perceive infinity as an indeterminate form. Students do not know the differences between limiting and functional value of the function. The result shows that misconception persists in all of them. This supports the claim that the limit concept causes some conceptual difficulty in learning.

\section{Conclusion and Implication of the Study}

The result of the study highlights some light on how students think about limits. The findings of the study reveal that students take the mathematical concept as an isolated fact rather than interconnected concepts. For instance, to understand the limit of the function, first students should have the concept of functions. Regarding the limit of the function, most of the students see it as unreachable object. The result of this study indicates that our students' skill in limit is only mechanical. This type of skill is also known as an instrumental understanding of the content (Skemp, 1976). As Tall (1991) described the three worlds, our students have problem in first 
conceptual-embodied world. The concept they made in learning limit was incomplete and filled with misconceptions. That means they have difficulties to enter into the perceptual-symbolic world and then formal-axiomatic world. Student can understand the concept clearly only when teacher presents content holistically and participate the learners actively in teaching learning process. For instance, without giving the clear idea about the relationship between $\varepsilon-\delta$, how do students can get clear picture of limiting and functional value of the function. $\varepsilon$ and $\delta$ are not merely the symbols, they carry the geometrical meaning. But, none of the teachers of sample schools had defined limit by using $\varepsilon$ and $\delta$ and then it is obvious that students took limit as only the approachable value of the function.

This small-scale study would provide a way-out about the curriculum restructuring and reframing. During interview, I found several imbalances on our teaching process and students' learning pattern. Teaching becomes meaningful only after students learn. Therefore, teacher should rethink on his/her instructional design. Limit of the function is the initial part of the calculus. So, based on the findings of this research, further research on calculus learning can be done in future.

\section{References}

Alam, A. (2020). Challenges and possibilities in teaching and learning of calculus: A case study of India. Journal for the Education of Gifted Young Scientists, 8(1), 407-433. doi:https:// doi.org/10.17478/jegys.660201.

Areaya, S. \& Sidelil, A. (2012). Students' difficulties and misconceptions in learning concepts of limit, continuity and derivative. The Ethiopian Journal of Education, 32(2), 1-37.

Brown, D. E. (1992). Using examples and analogies to remediate misconceptions in physics. Journal of Research in Science Teaching, 29, 141-178. Retrieved from http://www.jstor. org/stable/1466837? origin=JSTOR-pdf

Creswell. J. W. (2015). Research design: qualitative, quantitative, and mixed methods approaches. Singapore: Sage.

Eade, F. (2003). Secondary trainee teachers' understanding of convergence and continuity. International Journal of Mathematical Education in Science and Technology, 34, 371384.

Ervynck, G. (1981). Conceptual difficulties for first year university students in the acquisition ofthe notion of limit of a function. Paper presented at the Fifth Conference of the

International Group for the Psychology of Mathematics Education.

Fisher, K. (1985). A misconception in biology: Amino acids and translation. Journal of Biology Education, 22, 53-62.

Hiebert, J., \& Carpenter, T. P. (1992). Learning and teaching with understanding. In D. A. Grouns (Ed.), Handbook of research on mathematics teaching and learning (pp. 65-92). New York: Macmillan. 
Juter, K. (2006). Limits of functions as they developed through time and as students learn them today. Mathematical Thinking and Learning, 8, 407-431.

Kilpatrick, J., Swafford, J., \& Findell, B. (2001). Adding it up: Helping children learn mathematics. Washington: National Academy Press.

Lam, T. T. (2009). On in-service mathematics teachers' content knowledge of calculus and related concepts. The Mathematics Educator, 12(1), 69-86.

Muzangwa, J \& Chifamba, P. (2012). Analysis of errors and misconceptions in the learning of calculus by undergraduate students. Acta Didactica Napocensia, 5(2), 1-10. Retrieved from: https://files.eric.ed.gov/fulltext/EJ1054301.pdf.

Ojose, B. (2015). Common misconceptions in mathematics: Strategies to correct them. Maryland: University Press of America.

Robert, A., \& Speer, N. (2001). Research on the teaching and learning of calculus/elementary analysis. In D. Holton (Ed.), The teaching and learning of mathematics at university level: An ICMI study (pp. 283-299). Netherlands: Kluwer Academic Publishers.

Kula, S.\& Guzel, E. B. (2014). Misconceptions emerging in mathematics student teachers; limit instruction and their reflection. Quality \& Quantity, 48, 3355-3372. doi: 10.1007/ s11135-013-9961-y.

Siegler, R. S. (1986). Children's thinking. United States: Prentice-Hall.

Skemp, R. R. (1976). Relational understanding and instrumental understanding, Mathematics Teaching, 77, 20-26.

Skemp, R. R. (1979). Intelligence, learning, and action. New York: Wiley.

Tall, D.O. (1991) Advanced Mathematical Thinking: Kluwer Academic Publishers, 9-10

Tall, D.O. (2004). Thinking through three worlds of mathematics. Proceedings of the 28th Conference of the International Group for the Psychology of Mathematics Education, Bergen, Norway, 4, 281-288. Retrieved from homepages.warwick.ac.uk/staff/David. Tall/themes/three-worlds.html

Vinner, S. (1991). The role of definitions in teaching and learning of mathematics. In: Tall,

D.(Ed.) Advanced mathematical thinking,. Dordrecht: Kluwer.

Watson, A, \& Sullivan, P. (2008). Teachers learning about tasks and lessons. In D. Tirosh, \& T. Wood (Eds), Tools andresources in mathematics teacher education (pp. 109-135). Rotterdam: Sense Publishers.

Williams, S. R. (1991). Models of limit held by college calculus students. Journal for Research in Mathematics Education, 22, 219-236. Retrieved from http://psycnet.apa.org/ doi/10.2307/749075 